\title{
A comprehensive analysis of expenditure decentralization and of the composition of local public spending ${ }^{(*)}$
}

\author{
Agnese Sacchi \\ 'Universitas Mercatorum' University (Italy) \\ E-mail: a.sacchi@unimercatorum.it \\ Simone Salotti \\ Oxford Brookes University (UK) \\ E-mail: ssalotti@brookes.ac.uk
}

\section{This draft: November 2013}

\begin{abstract}
Many industrialized countries have recently implemented fiscal decentralization reforms assigning more competences and spending responsibilities to sub-national governments. In this paper we investigate what leads to the decentralization of different categories of public expenditure in 19 developed countries over the period 1980-2006. Adopting a general-to-specific empirical approach, we estimate different models for each of the spending functions under analysis. Our results confirm existing findings on the negative link between regional income disparities and expenditure decentralization. A similarly negative relationship is found for a set of demographic variables, leading to the conclusion that macroeconomic and, more importantly, political factors are the key to explain the recently increased decentralization levels in most industrialized countries. Finally, we complete our analysis by studying what determines the sub-national expenditure composition, finding that political and demographic changes are the most important factors in shaping the local spending mix.
\end{abstract}

Keywords: fiscal decentralization, COFOG, local revenue, macroeconomics, political institutions JEL classification: $H 750, H 760, H 770, E 020$

(*) We wish to thank Emma Galli, David Horan, Santiago Lago-Peñas, Federico Revelli, and seminar participants at the Oxford Brookes University, the XXIV Conference of the Italian Association of Public Economics (Pavia, September 2012), and the XX Meeting on Public Economics (Sevilla, January 2013) for useful comments on a previous version of this paper. Special thanks are due to the Editor and two anonymous referees for insightful suggestions. The usual disclaimer applies. 


\section{Introduction}

Major decentralization processes have occurred over a relatively short time period in traditionally unitary European countries (such as France, Italy, and the United Kingdom), some of which now show decentralization levels that are comparable to those of federal countries (Ter-Minassian 1997; Stegarescu 2005). These reforms have sparked a lively debate leading to a recent wave of studies on fiscal decentralization in both developed and developing countries (see, among others, Arzaghi and Henderson 2005, Bodman and Hodge 2010).

The existing literature offers a high number of mainly empirical contributions on determinants of fiscal decentralization such as income per capita, country size, and urbanization (Dafflon 1992; Wallis and Oates 1998; Panizza 1999; Letelier 2005). More recently the attention has shifted towards the investigation of additional variables capable of shaping decentralization such as regional inequality (e.g., Beramendi 2007; Stegarescu 2009; Sacchi and Salotti 2013). However, with all efforts concentrated on the determinants of fiscal decentralization as a whole, little has been said on what leads to decentralize specific government functions.

In particular, the characteristics and the driving forces of the decentralization of the various expenditure categories such as those included in the Classification Of the Functions Of Government (COFOG, provided by the United Nations) have been largely overlooked. ${ }^{1}$ The importance of using a high level of details such as the one offered by the COFOG classification in studies on decentralization has been recognized, among others, by Fiva (2006). ${ }^{2}$ However, these expenditure categories have only been studied in different contexts, such as those related to efficiency/government

\footnotetext{
${ }^{1}$ A notable exception is Letelier (2005) even though he considers only three cases of expenditure by function, i.e. education, housing, and health. Moreover, only a few explanatory variables (i.e., urbanization, population density, income and grants) are included into the empirical analysis. In general, public expenditure can be classified according to the following ten COFOG functions (policy domains): general public services; defense; public order and safety; housing and community amenities; economic affairs; environment protection; health; recreation, culture and religion; education; social protection. Each of them includes both current and capital expenditure. This makes the COFOG method different from the ECOG (Economic Classification of Government Expenditure) one, where total spending is divided into current and capital expenditure and then further into goods and services versus transfers. Hence, ECOG classifies expenditure by economic characteristics; COFOG by the function or purpose served. As we will explain later, in this paper we adopt the COFOG approach as provided by IMF.

2 "Separating public spending according to the United Nations Classification of the Functions of Government (COFOG) could be useful. Unfortunately, there is, as far as I know, no reliable longer time series available in the cross-country setting for this classification" (p. 260).
} 
size (Shelton 2007; Ashworth et al. 2012), or to political economy considerations (Brender and Drazen 2009; Creedy and Moslehi 2009). ${ }^{3}$

One of the main contributions of our paper is to fill this gap in the literature, providing a further step towards the understanding of the multi-faceted phenomenon of fiscal decentralization. Indeed, assuming that a single decentralization index can capture all the different objectives served by the various expenditure categories of the government, as it has been done so far, can be seen as the first step of the broader research agenda to which we are contributing.

The strategy of collapsing the whole activity of the public sector into a single expenditure measure seems particularly problematic when the institutional system is populated by many hierarchical authorities participating in the decision-making process. Moreover, the various expenditure items and different spending programs are designed to meet different individuals' needs (such as being educated, healthy, living in a safe environment) and to accomplish different governments' tasks (e.g., production of public services, redistribution, capital accumulation, etc.), making them unlikely to be driven by the same set of considerations.

We take all these aspects into account to fulfill two aims. First, we offer some evidence on the demographic, political, and macroeconomic determinants of decentralization of different expenditure categories (e.g., healthcare, education, social welfare, housing, transports, public order and safety) in developed countries, providing new insights to the existing literature mainly based on expenditure decentralization as a whole.

Second, we shed some light on what drives the allocation of resources across different expenditure policies at the local level. This is yet another topic overlooked by previous empirical studies. However, it is an area in which further knowledge is needed in order to go beyond the normative prescriptions of the traditional theory of fiscal federalism (Stigler 1957; Musgrave 1959) that simply prescribes to assign the allocation function to sub-central governments (with central governments retaining stabilization and redistribution). The literature has provided both equity- and efficiency-related justifications for this partitioning of the public sector, but it has not investigated the

\footnotetext{
${ }^{3}$ A notable exception is a recent empirical study by the OECD (2012) that links the degree of decentralization of government spending on education to assess the extent to which educational outcomes are influenced by subcentral powers and school autonomy.
} 
determinants of the local budget composition. Thus, we study the driving forces (e.g., demographic conditions, political ideology) behind the allocation of resources among the various COFOG functions in the local budget.

More generally, the rationale of studying the determinants of expenditure decentralization as well as those of the local spending composition lies, firstly, in the fact that most decentralizing countries (even in the Eurozone) lacked clearly designed expenditure decentralization strategies. Sub-central governments seem to be engaged in diverse policy and spending functions depending on the extent of decentralization. As a result, in highly centralized countries the bulk of sub-national spending refers to local services such as education (mainly preschool, primary and secondary), economic affairs, recreation and other residential services. In more decentralized countries the spending structure is usually different, with health (e.g., hospitals and basic healthcare) and social welfare (e.g., social housing) becoming relatively more important, while education remains a core responsibility (OECD 2012). Overall, the existing empirical evidence on decentralization of spending items is scarce mostly due to data availability issues - and large spending conglomerates are normally used (e.g., Persson and Tabellini 2003; Kappeler and Valila 2008; Rodríguez-Pose et al. 2009).

Secondly, the focus on the expenditure side is grounded on the fact that governments tend to decentralize expenditure execution more than revenue collection (IMF 2011). There is a welldocumented mismatch between revenue and expenditure decentralization in most countries, in what has been labeled as vertical fiscal imbalance (Eyraud and Lusinyan 2013). This feature has been taken into account in recent studies on fiscal decentralization (e.g., Jin and Zou 2002; Rodden 2003; Fiva 2006; Gemmell et al. 2013) where the distinction between decentralization of taxing powers and of spending powers is a key feature of most analyses. Not only we acknowledge this distinction, but we also take into account the role of grants besides that of decentralized revenues.

Using a general-to-specific empirical approach for a sample of 19 developed countries over the period 1980-2006, we adopt different models for each of the spending function under analysis providing a highly comprehensive picture in each case thanks to a wide set of explanatory variables included in the regressions. We take advantage of the previous empirical studies by using variables that have been found to significantly affect aggregate measures of fiscal decentralization (see Section 
2 for details). We implement several estimation techniques to ensure the robustness of our results, also taking into account potential endogeneity and reverse causality issues. In addition to using annual data, we offer results based on three- and four-year periods to ensure that we are dealing with longrun effects, rather than short-run, less-interesting outcomes. We then use the same framework to analyze the composition of the local budget, investigating what determines the weights of each spending category over local expenditure.

In both cases, we aggregate data from several different sources, taking the COFOG expenditure decentralization series from OECD and, especially, IMF Government Finance Statistics (GFS) databases.

We offer new insights on the determinants of the decentralization process of the single expenditure functions. First of all, we find different results and implications for different spending items, a fact that supports the soundness of our research question. We highlight a number of cases in which the influence of the explanatory variables differs across public spending categories when discussing the econometric results. Second, higher inter-regional income disparity suggests the avoidance of expenditure decentralization according to equity considerations; this is particularly true for social protection and welfare. Second, recent developments related to the population structure have mostly slowed down the decentralization process for social protection, housing and transport spending. Third, the reasons for the recent increased expenditure decentralization reforms in most countries must be traced back to macroeconomic factors, and even more importantly, political and institutional factors. For instance, more political pluralism leads to higher decentralization, especially for the functions linked to redistributive content (e.g., healthcare).

As for the local expenditure composition analysis, it emerges a lower importance of macroeconomic developments with respect to political and demographic changes in shaping the local spending mix. Even if results differ across the various categories, a common trend seems to emerge: sub-central governments have an incentive to spend more on productive investment such as housing policies or education and less on other spending items. In particular, local education spending is likely to be favored by higher levels of income and political pluralism, and healthcare favored by faster population growth and both moderate-left and moderate-right cabinets. 
The plan of the paper is as follows. Section 2 illustrates the empirical strategy to study the determinants of expenditure decentralization and the variables used in our analysis. Section 3 presents and discusses the estimation results on expenditure decentralization by function. Section 4 analyses the composition of local public spending. Finally, section 5 concludes and provides some policy implications.

\section{Expenditure decentralization by function: the empirical strategy}

\subsection{Model, variables, and data}

What leads to the decentralization of the different COFOG spending categories? In this section we lay out our strategy to study the importance of a large number of demographic, political, macroeconomic and fiscal variables, controlling for the degree of tax decentralization and the weight of intergovernmental grants as financing tools for sub-central government spending. We concentrate on developed countries to increase the reliability of the results in terms of cross-country comparisons. ${ }^{4}$ The choice of the sample under investigation is, to a certain extent, dictated by data availability, particularly because of the lack of fiscal decentralization data after 2006 and of regional economic disparities data before 1980 .

The empirical results on expenditure decentralization by function are based on the following model:

$$
\exp \_\operatorname{dec}_{i, t}=\alpha_{i, 0}+\boldsymbol{\beta}_{i, j}^{\prime} \text { macro }_{i, t}+\boldsymbol{\beta}_{i, k}^{\prime} \text { demo }_{i, t}+\boldsymbol{\beta}_{i, l}^{\prime} \mathbf{p o l}_{i, t}+\alpha_{i, 1} \operatorname{tax}_{-} \operatorname{dec}_{i, t}+\alpha_{i, 2} \operatorname{grants}_{i, t}+\tau_{t}+u_{i, t},
$$

where $\exp _{-} d e c_{i, t}$ stands for local spending (net of intergovernmental grants ${ }^{5}$ ), as a share of general government expenditure within a certain COFOG category. Using this general definition, we estimate seven different specifications, starting from aggregate local expenditure (tot_dec) and following with

\footnotetext{
${ }^{4}$ The countries are: Australia, Austria, Belgium, Canada, Denmark, Finland, France, Germany, Greece, Ireland, Italy, Netherlands, Norway, Portugal, Spain, Sweden, Switzerland, United Kingdom, and United States.

${ }^{5}$ Money transfers received from other government levels are excluded from local spending to avoid including grants on the right- as well as on the left-hand-side of the regression equation. Thus, we controlled for received grants only in the right-hand-side of the equation. Moreover, money transfers from local to other government levels - although less frequent than the others - are also excluded from local spending in order to correctly appraise their policy domains and sizes.
} 
the main public functions: health (hea_dec); education $\left(e d u \_d e c\right)$; social protection and welfare (soc_dec); housing (hou_dec); transports $\left(t r a \_d e c\right)$; public order and safety (ord_dec). The values of these variables can therefore be read as the percentages of decentralized spending within each category. ${ }^{6}$ We treat the first case in order to make our study consistent with the standard approach adopted by the existing literature, which mainly deals with spending decentralization as a whole, without differentiating among expenditure functions.

The empirical literature on the determinants of decentralization has generally lacked theoretical foundations (see Treisman 2006 for further details). Moreover, since this is one of the first attempts to understand what drives the decentralization of specific functions, we build on the studies on expenditure decentralization as a whole for the choice of the variables to include in our analysis. Then, we study the COFOG functions with specific models obtained via the general-to-specific approach as explained below.

The explanatory variables are divided into three main groups. ${ }^{7}$ macro is a set of macroeconomic and fiscal indicators included on the basis of the literature considering these elements among the determinants of fiscal decentralization (e.g., Wagner's Law; the globalization theory of Rodrik, 1998; the Bolton and Roland's - 1997 - 'political factor' arising from differences in income distribution across regions). The variables are the following: a) $g d p p c_{i, t}$ is the logarithm of real GDP per capita which is expected to be positively correlated with expenditure decentralization as previously documented by some scholars (e.g., Bahl and Nath 1986; Wallis and Oates 1988; Panizza 1999; Letelier 2005); b) regdisp ${ }_{i, t}$ is regional economic disparities measured by the population-weighted coefficient of variation (calculated as the standard deviation of per capita regional GDP within a country divided by the country's per capita GDP level): it is expected to negatively affect the demand for decentralization in favor of a stronger central government's intervention according to equity reasons (see, e.g., Wibbels 2005; Rodden 2010; Sacchi and Salotti 2013); c) govsize is is the government consumption share of GDP, to consider policymakers' behavior in shifting spending

\footnotetext{
${ }^{6}$ We leave defense decentralization out of the analysis, being it a category which is hardly decentralized. The average amount of decentralized defense spending in our sample is only $0.06 \%$. Results for this particular spending category would not be particularly insightful.

${ }^{7}$ Table A1 of the Web Appendix contains some descriptive statistics of the variables used in the analysis, and the detailed definitions and sources.
} 
competencies among government levels in order to increase efficiency and reduce the potential deficit-bias. d) $\mathrm{open}_{i, t}$ is trade openness measured by the sum of imports and exports divided by GDP, which may have an ambiguous impact on expenditure decentralization. On the one hand, more open economies might be forced to enhance redistributive programs and stabilization policies by increasing the role of central governments (Garrett and Rodden 2003). On the other hand, countries may benefit from increased competitiveness and greater access to external financing sources (de Mello 2005) resulting in a leaner and more decentralized public sector. In our case, openness may show positive sign for the expenditures that can rely more on the market for financing purposes. The last macro variable, e) $d e b t_{i, t}$ is gross public debt divided by GDP. It is a fiscal stock variable related to the size of the government, capturing its long-term behavior rather than the yearly-specific fiscal conditions.

The set labeled demo contains the following demographic variables taken from the empirical literature on the role of demand and supply for specific expenditure categories (e.g., Letelier 2005; Shelton 2007): a) $u r b_{i, t}$ stands for urbanization (measured by the percentage of urban population over

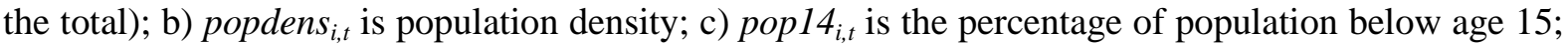
d) $p o p 65_{i, t}$ is the percentage of population above age 65; e) popgr $_{i, t}$ is the growth rate of the total population; f) lifexp $_{i, t}$ is life expectancy at birth; g) $e d u c_{i, t}$ is tertiary school enrolment, and it proxies for public awareness. More precisely, more urbanization may call for more expenditure centralization by attracting the rural population towards big centers, favoring a certain concentration of public expenditure. Population density may be, on the one hand, negatively related to decentralization if the economies of scale in the provision of public goods and services prevail; on the other hand, if a higher population density proxies for more heterogeneous preferences of individuals (Letelier 2005), there could be a positive correlation of the former with decentralization. The variables on the population structure approximating the size of the non-working population (pop14 and pop65) may also have ambiguous effects on decentralization. Positive, as in Shelton (2007), with a greater fraction of the population over 65 associated with large and significant increases in local government expenditure in almost every category. Negative, if larger percentages of non-working population lead to greater demand for redistribution, normally better accomplished by central spending programs. 
Finally, pol is a set of political and institutional variables representing the degree of political stability and capturing the heterogeneity of individual preferences reflected in the voting results, all of which can differently affect different public spending programs (Persson and Tabellini 1999, 2003; Milesi-Ferretti et al. 2002; Brender and Drazen 2009). The variables are the following: a) party_right,centre_r,centre_l,left $t_{i, t}$ are dummies taking the value 1 in each period with dominance/hegemony of either right (_right__centre_r) or left (_leftl_centre_l) in the cabinet (the reference/missing category being a balanced cabinet); b) pluralism ${ }_{i, t}$ is a variable accounting for political pluralism (it takes higher values for effective legislatures, competitive nominating processes, and good party legitimacy); c) direct_elect $t_{i, t}$ is an ordinal variable indicating if local governments are directly elected by the local population that they govern, indicating a sort of "legitimacy" of subcentral governments within the institutional system (it takes higher values when more local government tiers are directly elected). More pluralism and direct elections may favor more decentralization in light of the higher accountability allowed to citizens by this kind of political institutions. As for the role of political parties, there might be significant differences in the fiscal behavior of ideologically opposed parties for certain policies (e.g. left governments are thought to be more favorable to expansionary policies). However, the expected signs on decentralizing expenditure are not a priori obvious.

Beyond these explanatory variables, it is important to control for the financing sources of subnational governments. We do it by distinguishing the way through which local governments finance their expenditures, i.e. common pool versus own resources. This may affect the expenditure side, although tax and spending decentralization decisions are not necessarily taken together. Accordingly, the basic idea of the 'Second Generation Theory' of fiscal federalism is that a decentralization process with local governments relying on their own resources would be more efficient than one based on transfers.

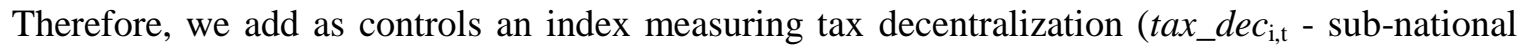
revenue minus grants from other levels of government, divided by general government revenue), ${ }^{8}$ and

\footnotetext{
${ }^{8}$ We use the "own revenue" tax decentralization index constructed by Gemmell et al. (2013) that captures a wide degree of local taxing power as it contains also locally collected taxes over which local governments have
} 
the ratio between transfers received by sub-national governments from upper levels and general government revenue minus intergovernmental grants $\left(\operatorname{grants} 1_{i, t}\right)$. Consistently with the common pool theory, the expected sign on grants is positive, while that on tax decentralization may be negative according to the Leviathan hypothesis or positive if expenditure decentralization decisions go handin-hand with the increase in taxing power of local governments.

Before getting to the analysis, it is worth spending a few words on the IMF-GFS data. GFS data suffer from well-known limitations, the most relevant concerning the overestimation of the real autonomy of sub-central governments over their expenditure and tax decisions. Unfortunately, even though improved tax decentralization indices have been constructed by researchers starting from this source (Stegarescu 2005; Gemmell et al. 2013), on the expenditure side it is yet impossible to find higher quality data. ${ }^{9}$

However, the COFOG disaggregation of local expenditure offers the advantage of being homogeneous across the various countries of the sample. It also avoids large aggregates such as government consumption (used in Fiva 2006) or redistributive spending (in Persson and Tabellini 2003). More generally, the strength of our dataset consists in allowing a closer look at both crosssectional and inter-temporal variation in government expenditure considering both individual categories of expenditure and different levels of government, i.e. central and sub-central, with a high degree of detail. For instance, public order and safety expenditure includes police, fire-protection services, law courts, prisons, R\&D related to public order, and safety spending. Likewise, housing expenditure includes many items such as housing development, community development, water supply, and street lighting. Among the redistribution-related functions, healthcare covers spending in medical products, appliances and equipment, outpatient, hospital and public health service, and related R\&D.

little or no control. In detail, it includes shared taxes and other piggybacked revenues at a local level, not distinguishing them from more autonomous forms of taxation. However, the index is net of resources purely transferred from other governmental levels (i.e. grants); therefore, it only contains the revenues generated by sub-national governments and which are not discretionarily fixed by central government.

${ }^{9}$ It is important to acknowledge that all these data do not allow any distinction among regional, local, and other lower tiers of governments: all sub-national units are aggregate into a single group; therefore, the number of participating sub-central governments and their different competencies are not properly taken into account. However, a further horizontal disaggregation would pose cross-country comparability issues that we want to avoid at this stage of the analysis. 
Beyond the abundance of information within each expenditure category, the rationale for using this disaggregated dataset lies in the fact that explanatory variables exhibiting certain correlations with decentralized aggregate spending may behave very differently when put to the test of disaggregated data. We accordingly offer new interpretations on single spending categories, revealing a more intricate pattern than so far presumed.

\subsection{The estimation techniques}

We adopt different estimation techniques all based on the general-to-specific approach that (potentially) leads to different models for each of the different spending categories. The procedure works as follows: for each government function, we start by estimating with a fixed effects (FE) panel estimator the most comprehensive model, i.e. including all the right-hand-side variables described above. Then, we eliminate the variable exhibiting the lowest $t$-statistic if minor than 1.00 , and we estimate the new, more parsimonious model, and check its diagnostics. We continue with the variable elimination until none of the remaining variables can be eliminated, i.e. all the $t$-statistics are larger than 1.00 . We set the threshold equal to 1.00 in order to make it easier to identify possible regularities across spending categories (setting a higher threshold would reduce the number of variables included in the models, making it harder to identify common patterns), and also to increase the probability of retaining relevant variables (Campos et al. 2005). This procedure implies that each one of the expenditure specifications will differ depending on the explanatory power of the right-hand-side variables in each case.

After having obtained the specifications as just explained, we estimate the model in equation (1) with two different estimators in addition to the FE one, that we use as a benchmark as it controls for country-specific time-invariant factors such as country size, ethnic fragmentation ${ }^{10}$, and institutional factors (e.g., whether the country is federal). We offer estimates based on the Feasible Generalized Least Squares (FGLS) method to take into account potential cross-sectional correlation. This estimator is considered to be efficient for the sample dimensions that we are handling here (Beck and

\footnotetext{
${ }^{10}$ Actually, the degree of ethnic fragmentation may change over time, although slowly. However, the only available data (see Alesina et al. 2003) are time-invariant.
} 
Katz 1995). Finally, we present results obtained with the two-step efficient GMM estimator to deal with potential endogeneity of some of the explanatory variables (see sub-section 3.2 for details). In all cases, equation (1) is estimated using annual frequency data from 1980 to 2006 on a sample of 19 OECD countries; period dummies are also included $\left(\tau_{t}\right)$, and $u_{i, t}$ is the disturbance term.

\subsection{The long-run analysis}

The empirical analysis is completed by the following model estimated using three- and four-year nonoverlapping periods in order to capture long-term effects:

$$
\exp \_\operatorname{dec}_{i,[t, t+n]}=\phi_{i, 0}+\boldsymbol{\varphi}_{i, j}^{\prime} \mathbf{m a c r o}_{i, t}+\boldsymbol{\varphi}_{i, k}^{\prime} \mathbf{d e m o}_{i, t}+\boldsymbol{\varphi}_{i, l}^{\prime} \mathbf{p o l}_{i, t}+\phi_{i, 1} \operatorname{tax}_{-} \operatorname{dec}_{i, t}+\phi_{i, 2} \operatorname{grants}_{i, t}+\omega_{t}+\varepsilon_{i, t}(2)
$$

The use of data at multi-year periods' frequency is customary in macroeconomics when concentrating on long-run phenomena, given that it permits to avoid the volatility arising from shortterm business cycle fluctuations. Therefore these additional estimates ensure that our empirical model is not capturing short-term relationships when using annual data. Additionally, this method offers a simple way to take into account potential reverse causality, as the dependent variable is expressed as the period average values, while all the right-hand-side variables are expressed as beginning-of-theperiod values (for similar applications, see, among others, Barro and Lee 2005). Rather than estimating equation (2) with five-year periods data, which would severely limit the time dimension of the sample, we do it with both three- and four-year periods data to ensure consistency. Period dummies $\left(\omega_{t}\right)$ are included, and $\varepsilon_{i, t}$ is an error term.

\section{The decentralization of the COFOG expenditures: results and discussion}

\subsection{Benchmark results}


Table 1 reports the results for the seven different specifications of equation (1) using the FE panel estimator. The results of Sargan tests reported in the last row support the choice of this estimator over the random effects one.

\section{Insert Table 1 about here}

Among the many results, it clearly emerges the role of regional economic disparities (regdisp) that, when included, are always associated with negative and highly statistically significant coefficients. This indicates that higher regional inequality contributes to reduce the incentives for expenditure decentralization both in aggregate terms and for specific items such as social and transport spending. The result for aggregate expenditure decentralization (tot_dec) is consistent with previous findings by Stegarescu (2009) and Sacchi and Salotti (2013). The intuition lies in the fact that higher levels of inequality across territories are likely to increase the demand for inter-regional redistribution that could be better satisfied by the central government's intervention (Wibbels 2005). The larger coefficient in the case of social welfare than in the aggregate expenditure case $(32.59$ versus 22.37) implies an even greater effect for social spending that is consistent with our interpretation. According to our estimates, differences in regional disparities alone explain a $3 \%$ higher expenditure decentralization in Austria with respect to Belgium, the latter being characterized by much higher regional economic inequality.

As for the rest of the macro variables, higher real GDP per capita does not favor decentralized expenditure for health and public order purposes, while it leads to more decentralized education spending. The latter result can be justified by considering education spending at the local level as a desirable but expensive and superior good that can only be afforded by affluent societies (as put forward by Tanzi, 2000, although referred to fiscal decentralization in general), while decentralized public order and safety can be treated as "normal" goods (whose decentralization should not necessarily increase with per capita income). For instance, the higher French GDP per capita over the Spanish one justifies a 10\% lower health expenditure decentralization and a 5\% higher education decentralization in France, all else equal. An inverse relationship between income and health 
decentralization is also empirically found by Letelier (2005) and theoretically supported by Oates (1972) and Gordon (1983).

The higher the importance of the government in the economy, measured by govsize, the lower the pressure for total expenditure decentralization (for example, the higher importance of public spending in Greece with respect to Ireland implies a $2 \%$ less decentralized structure, ceteris paribus), as well as for specific spending items such as healthcare. The positive sign of trade openness in the case of decentralized education spending seems to contrast with the globalization theory according to which more economic integration may call for more central government expenditure for redistributive and stabilization purposes, i.e. the so-called "compensation hypothesis" (Cameron 1978). However, under the "efficiency hypothesis" (Swank 1998) globalization can foster competition between countries to attract FDI leading to a reduction in taxation (particularly capital taxes), and so the size of the public sector, and to a restructuring in the composition of government expenditure towards privately productive public inputs. This supports the finding of a positive impact of trade openness on the decentralization of spending items such as transport (which includes communication) and education. As for the transport expenditure decentralization, a 5\% difference between Ireland and the UK is implied by the sole higher trade openness of the former (note that the openness index is also inversely - and inevitably - related to country size).

The demographic variables (demo) prove to be particularly relevant for the decentralization of all expenditures, being mostly associated with negative coefficients across the various spending categories. For instance, the proportion of people aged less than 14 years old always shows negative coefficients, highlighting that the presence of this part of the population calls for more fiscal centralization, particularly in the case of housing policies. For instance, this variable alone may explain a 5\% more centralized housing expenditure in Denmark versus Switzerland. Similarly, the share of elderly population demands less decentralization for welfare-related spending (and housing), while it positively influences transport expenditure decentralization. Population density and population growth show mixed effects (the former is positively associated with decentralization of education expenditure, but negatively with that of transport and social spending; population growth is positively associated with healthcare and social spending decentralization, but negatively with 
housing decentralization), as in most of the existing literature. Panizza (1999), for example, demonstrates that a lower population density leads to a higher ideological distance from the median voter, lowering the demand for centrally provided public goods. In addition, low density countries are likely to be more costly and logistically difficult to administer from the centre (Bodman and Hodge 2010). On the other hand, Prud'homme (1995) argues that decentralization is more warranted in a densely populated country - where secondary sub-national units are still large - as to make the decentralization process successful, local governments should have the critical mass required to use their powers effectively. As an example, in our sample countries like Denmark, Finland and Sweden do not have intermediate levels of governments (e.g., regions) due to their small size or low population density.

Finally, the proportion of population living in urban areas is always associated with negative coefficients (when included in the model). Hence, urbanization is likely to induce more fiscal centralization for aggregate and healthcare spending. This may be due to the fact that the central government can autonomously improve public urban facilities, and this improved urban infrastructure could attract the population from the non-urbanized part of the country. The tertiary school enrolment (educ) shows a negative (when statistically significant) coefficient, which is consistent across specifications.

Among the pol variables, the political party dummies do shape the expenditure decentralization processes, but again results vary widely. Having left dominance in the cabinet (party_left) is associated with lower expenditure decentralization in education and public order. On the other side, right-wing hegemony in the cabinet (party_right and party_centre_r) positively affects decentralization of specific functions such as housing and public order, while it negatively affects it on the aggregate. In turn, political pluralism (pluralism) shows positive (when statistically significant) coefficients, suggesting that more pluralism leads to more fiscal decentralization, mainly of healthcare spending.

As for the revenue-side controls, tax decentralization (tax_dec) positively correlates with healthcare, education, housing, and transports expenditure decentralization. This suggests that tax decentralization is likely to accompany expenditure decentralization, increasing consistency between 
those that benefit from the programs and those who end up financing and paying for them, through charges and user fees for example. On the other hand, tax decentralization is not correlated with decentralized social and welfare spending, while the second revenue-side control, grantsl, is positively and highly correlated with it. This fits well with the practice commonly adopted by central governments that usually finance this type of function through intergovernmental grants, even when it is assigned to sub-central governments (OECD 2006, 2009).

A positive relationship between grants and decentralization also emerges for health expenditure (but at a lower significance level) confirming that even though this spending item can be decentralized, it may still be mandated by the central government or spent on behalf of it - given the collective interest for healthcare - revealing the importance of intergovernmental transfers as a financing tool combined with local taxation.

\subsection{Additional results}

As a first step to check the robustness of all these results, we re-estimated the model specifications obtained with the benchmark analysis using the FGLS estimator with country fixed effects and controlling for heteroskedasticity in order to take into account possible cross-sectional correlation.

Table A2 (in the Web Appendix) shows that practically all the benchmark results hold. In particular, the important role of regional economic disparities and of most of the other macroeconomic variables is still evident, as well as the mostly negative role played by demographic developments in shaping decentralization of most spending categories. Moreover, the statistical significance of the demo variables coefficients is higher in the cases of social spending and housing decentralization, while the pol variables lose their explanatory power in the case of decentralized public order expenditure. Finally, these new estimates also confirm the positive correlation between tax and expenditure decentralization.

A second, and possibly more important, step to validate the results presented above is to take into account potential issues related to endogeneity. Some of the right-hand-side variables of model (1) may not only influence fiscal decentralization, but may also be influenced by it. For example, fiscal decentralization can affect the aggregate size of the public sector, although there is no consensus in 
the literature on the sign of this effect (see, among others, Prohl and Schneider, 2009, supporting a negative relationship, and Cassette and Paty, 2010, providing evidence for a positive one). These arguments naturally lead to also think about the possible endogeneity of public debt, which is substantially related to government spending. More generally, fiscal decentralization might affect the fiscal stability of a country altering the major fiscal outcomes such as budget deficit (Neyapti 2010) and public indebtedness (Baskaran 2010). Another macroeconomic variable that may be affected by decentralization is regional disparity, although the causality should mainly run from the latter to the former, and not vice versa (see Sacchi and Salotti 2013).

There are three other variables that may be suspected of being endogenous in our model. The first two are urbanization and population density, which could change depending on decentralization according to the voting-by-feet theory (Tiebout 1956) and to increased horizontal competition across local governments potentially altering the individuals' working and living decisions. The third is life expectancy, as it has been hypothesized that fiscal decentralization may indeed affect individuals' health (Jiménez-Rubio 2010).

Therefore, Table 2 contains the results of the seven specifications of model (1) estimated with the two-step efficient GMM estimator where we treat the variables mentioned above (govsize, debt, regdisp, urb, popdens, and lifexp) as endogenous, if present. ${ }^{11}$ We instrument these variables with their second and third lags (and with the levels of the rest of the right-hand-side variables included in the model).

\section{Insert Table 2 about here}

First of all, the available diagnostics supports the soundness of most of the specifications, as only in one case the Hansen test of overidentifying restrictions rejects the validity of the instruments. ${ }^{12}$

\footnotetext{
${ }^{11}$ We obtain similar results with the 2 SLS estimator, not reported for the sake of brevity. Also, the public order and safety (ord_dec) results are equal to those of Table 1, since none of the now-considered endogenous variables is included in that expenditure specification.

${ }^{12}$ The test rejects the null hypothesis in the tra_dec specification. In one other case the null is rejected at $10 \%$ significance level only: edu_dec. However, with multiple endogenous regressors it is appropriate to check diagnostics with the Angrist-Pischke F-tests and the Cragg-Donald Wald tests, all of which display
} 
Second, almost all the estimated coefficients are in line with those of the benchmark: in all cases their signs are confirmed, and the values of the vast majority of them are also comparable. The main thing to notice seems to be the non-confirmation of the negative relationship between urbanization and expenditure decentralization, with the coefficient of the former being not statistically different from zero in the GMM estimation. There are other marginal differences in terms of statistical significance, but we can conclude that results do not substantially change when taking into account potential endogeneity concerns.

\subsection{Long-run results}

The third check of the findings arising from model (1) consists in estimating a version of it with data at a different frequency to make sure that we are dealing with long-run, meaningful relationships. Table 3 contains the FE estimates of equation (2) using three-year periods data (please refer to Table A3 of the Web Appendix for the four-year periods estimates, that are consistent with those reported here).

\section{Insert Table 3 about here}

These additional estimates support once again the benchmark findings. The main differences seem to lie in different levels of statistical significance of some of the coefficients. For instance, these results do not find evidence of a negative relationship between public debt and aggregate expenditure decentralization (the debt coefficient is not statistically different from zero), but they support a negative relationship between the latter and hegemony of center-left parties in the government. Thus, we conclude that the long-run results strengthen the findings of the benchmark specification, suggesting that they are robust to potential reverse causality issues and, even more importantly, that there are meaningful long-term relationships among our variables of interest.

appropriately high values (with the null hypotheses rejected at the 5\% significance level or less in all specifications). 


\section{The local budget composition: model and results}

In this section we complete our analysis of decentralized expenditure, exploiting our rich and comprehensive dataset, by studying the determinants of the resource allocation across different spending programs funded by the local budget. Being more decentralized is not a sufficient condition to conclude that all expenditures are equally developed at the local level, and we offer a deeper analysis on the forces driving the sub-central spending mix to better understand this phenomenon.

The theoretical literature on the issue only provides some normative prescriptions (Musgrave 1959; Oates 1972; Keen and Marchand 1997) by distinguishing among functions that sub-national governments should perform (e.g., allocation of resources) and those which are better accomplished at the central level (e.g., redistribution and stabilization).

The empirical literature has overlooked the potential impact of decentralization on the composition of public expenditures (see, e.g., Sanz and Velázquez 2002). The few existing studies on the topic only consider limited decompositions of the public budget, like investment versus current expenditure (Alegre 2010), or different types of public investment (Faguet 2004; Kappeler and Valila 2008), or pork barreling versus different expenditures (Diaz-Cayeros et al. 2002).

The COFOG definition has only been used in some decentralization studies such as Arze del Granado et al. (2005), testing whether higher levels of fiscal decentralization increase the shares of consumption expenditures in the public budget. Similarly, Ashworth et al. (2012) study the effects of fiscal decentralization on the composition of government growth, decomposing consolidated (total) expenditure into three different programs, each one as a percentage of GDP: healthcare, education and social security. Their results highlight the importance and the different impact of alternative financing tools on such expenditure items. ${ }^{13}$

Mimicking the analysis of Section 3, we estimate the following model to investigate what affects the composition of the local budget:

\footnotetext{
${ }^{13}$ First, grants have a positive effect on health expenditure but not on education and social security. Second, the greater is the proportion of own taxes collected at the local level, the lower the proportion that is spent on all the three items. Finally, it seems that more decentralization leads to larger shares of GDP spending on education, while for healthcare and social security the opposite pattern is true.
} 


$$
\exp \_c o m p_{i, t}=\xi_{i, 0}+\chi_{i, j}^{\prime} \mathbf{m a c r o}_{i, t}+\chi_{i, k}^{\prime} \mathbf{d e m o}_{i, t}+\chi_{i,,}^{\prime} \mathbf{p o l}_{i, t}+\xi_{i, 1} \operatorname{tax}_{-} \operatorname{dec}_{i, t}+\xi_{i, 2} \operatorname{grants}_{i, t}+\varsigma_{t}+v_{i, t},(3)
$$

where exp_comp $_{i, t}$ denotes seven different indices gauging the importance of each spending item (i.e. the six COFOG categories, excluding defense as before, plus one obtained as a residual component res_comp) over aggregate sub-national expenditures (excluding intergovernmental grants). The explanatory variables are those of equation (1), except grants $_{i, t}$ that stands for the weight of transfers (from other government levels) received by sub-central units, normalized on the basis of aggregate local revenues..$^{14}$

\section{Insert Table 4 about here}

Table 4 reports the results of the different specifications of equation (3) using the FE panel estimator (these are consistent with the FGLS results are reported in Table A4 of the Web Appendix). Most of the variables that proved to be important in shaping the process of expenditure decentralization also affect local spending composition. In general, the macro variables mainly affect the shares of the budget pertaining to health, transports and public order. Additionally, the positive impact of trade openness on education at the local level reflects a result in line with the globalization effect on certain spending items (mainly those with redistributive and risk sharing purposes) as suggested by Cameron (1978) first, and Rodrik (1998) later.

In turn, both positive and negative signs of per capita GDP on different functions reveal different income sensitiveness of these government expenditures at the local level. A higher level of income per capita increases the share of education and public order expenditures, while it decreases that of healthcare spending.

\footnotetext{
${ }^{14}$ Aggregate local revenues are defined as the sum of local tax revenues and grants from other government levels. Local non-tax revenues and local capital revenues are excluded from this definition as they are recorded irregularly.
} 
The pol variables (with the exception of party_right) play an even more important role. In detail, right dominance in the cabinet (party_centre_r) politics contributes to increase the share of education and social welfare items, while left dominance (party_left) is associated with lower local spending on education. Hence, education and social welfare appear to be the spending programs most sensitive to ideological issues. On the other hand, local decisions on health expenditure seem to be unaffected by political coalitions but rather driven by other forces.

Among the demo variables, population density developments concur to decrease the share of spending devoted to social welfare and housing, but raise the importance of education and public order expenditure components. On the other hand, we note a negative effect of non-working population (mainly pop65) on local education and housing policies, possibly due to the fact that this kind of population basically asks for more redistribution and healthcare. More generally, if the size of the non-working population increases (pop14 and pop65), the complementary share of working individuals shrink and less tax revenues are probably available to finance many kind of public expenditure also locally. This contributes to explain the negative estimated coefficients of some demographic variables (see also Ashworth et al. 2012).

Finally, we also estimate significant coefficients for the two revenue-side controls. Intergovernmental grants accompany the healthcare and housing components of the budget. This positive sign is consistent with the common pool hypothesis (see Weingast 2009 for a survey) according to which local governments favor the growth of local expenditure in general terms, instead of, for example, lowering the tax burden on their residents. As for healthcare (reporting the highest level of significance), it can be justified by the nature of such program that is usually spent locally but funded by the central government (e.g., with block grants) in many developed countries (e.g., Denmark, Italy, Sweden).

Likewise, the negative sign of the tax decentralization coefficient on the social welfare share of the budget proves that sub-central governments do not devote many resources for these spending programs even when higher degrees of tax autonomy and own resources are allowed. They prefer, instead, to invest in other sectors such as housing policies where the linkages between taxing and benefit areas are more effective and immediately visible at the local level, even if some positive 
spillovers to non-residents justify the existence of intergovernmental grants. The rest of the functions, such as education and healthcare, seem to be unaffected by tax decentralization (in the remaining specifications it is excluded from the model according to the general-to-specific methodology). This suggests that, in order to allocate resources from the local public budget towards different spending topics and thus choose the proper policy mix locally, the extension of the taxing power and revenue autonomy assigned to sub-national governments seems to play a negligible role.

As we did in the first part of our analysis, we checked the robustness of the results by estimating a version of model (3) using three- and four-year periods data to make sure that we were able to identify significant long-term relationships among the variables. The results, reported in Tables A5 and A6 of the Web Appendix, substantially confirm the above findings with only minor differences (mainly in terms of different significance levels, rather than different effects). ${ }^{15}$

\section{Summary and conclusions}

In this paper we study the determinants of expenditure decentralization and those of the local spending composition analyzing six different COFOG functions in 19 developed countries over the period 1980-2006. This research question is at the center of a lively debate sparked by the ongoing fiscal decentralization processes experienced by most industrialized countries with different trends and implementation strategies. As noted by the OECD (2012), most reforms have concentrated on the expenditure rather than the revenue side. Accordingly, we offer evidence on how political, demographic, macroeconomic and fiscal variables affect expenditure decentralization, controlling for the different financing mechanisms, i.e. taxes and grants. In the second part of the empirical investigation, we provide new insights on the determinants of the local budget composition. In both cases the literature does not offer a clear theoretical guidance, therefore we adopt a comprehensive

\footnotetext{
${ }^{15}$ It is conceivable to imagine a stronger econometric link between the two parts of the analysis, leading to the estimation of, for example, simultaneous equations models where the same explanatory variables determine, at the same time, both the amount of decentralized expenditure and the quota in the local budget. We feel that this could be an interesting further step to continue along the research lines initiated by our analysis here.
} 
demand-driven approach using a wide range of variables related to the various functions of the government.

We obtain the following results. First, even if a unique set of variables can be used to explain cross-country differences in fiscal decentralization (see, e.g., Panizza 1999), the analysis of different expenditure functions calls for different explanations with several factors at work. Second, the recent demographic developments in developed countries contributed to slow down the decentralization process of several spending components. A similarly negative influence on decentralization attitudes is found to be linked to regional economic disparities, with more unevenly distributed regional resources calling for more centralization of spending, especially those with redistributive purposes. Therefore, the reasons behind the increasing decentralization levels observed in recent decades are traced back to macroeconomic and political determinants.

Third, these relationships are robust across additional specifications taking into account potential endogeneity and reverse causality issues. The latter estimates in particular show that these results reflect meaningful long-term relations, rather than less interesting, short-term effects. Finally, political and ideology-related variables play a key role for the spending allocation at the local level, while macroeconomic variables seem to matter less. Demographic developments also concur in shaping the composition of the local budget.

In general, some of our results better qualify existing theoretical prescriptions. For example, those of the fiscal federalism mainstream on limiting decentralized redistribution are supported by our findings on the negative relationship between regional economic disparities and expenditure decentralization as a whole and, in particular, of social welfare. On the other hand, some of the evidence offered in this paper suggests that other generally accepted concepts should be reconsidered. For instance, a substantial part of the literature on fiscal decentralization typically assumes that lower levels of government both collect taxes and spend funds, so sub-national authorities can be classified either as low-tax-low services or high-tax-high-services (e.g., Bardhan 2002). However, this effective correspondence may be undermined by demographic changes affecting the population structure and the labor force, resulting in diverse local tax bases and revenues. All in all, this evidence calls for a better understanding of the decentralization reforms in countries where linkages between local tax 
autonomy and spending responsibility show a different strength degree, which is also a common feature in our sample.

Finally, further research may be devoted to the potential interactions among the various government functions and their repercussions on the inter-governmental fiscal design, especially when relevant decentralization reforms take place.

\section{References}

Alegre, J.G. (2010). Decentralization and the Composition of Public Expenditure in Spain. Regional Studies 44(8), 1067-1083.

Alesina, A., Devleeschauwer, A., Easterly, W., Kurlat, S., Wacziarg, R. (2003). Fractionalization. Journal of Economic Growth 8(June), 155-194.

Arzaghi, M., Henderson, J.V. (2005). Why Countries Are Fiscally Decentralizing. Journal of Public Economics 89, 1157-1189.

Arze del Granado, F.J., Martinez-Vasquez, J., McNab, R. (2005). Fiscal Decentralization and the Functional Composition of Public Expenditures. International Studies Program working papers no. 05-01, Georgia State University, Atlanta, GA.

Ashworth, J., Galli, E., Padovano, F. (2012). The effects of decentralization on the dynamics of public spending programs. CREM-CNRS Working Paper 2012/5.

Bahl, R. W., Nath, S. (1986). Public expenditure decentralization in developing countries. Environment and Planning C: Government and Policy 4, 405-418.

Bardhan, P. (2002). Decentralization of Governance and Development. The Journal of Economic Perspectives 16(4), 185-205.

Barro, R.J., Lee, J.W. (2005). IMF programs: who is chosen and what are the effects? Journal of Monetary Economics 52, 1245-1269.

Baskaran, T. (2010). On the link between fiscal decentralization and public debt in OECD countries. Public Choice, 145, 351-378.

Beck, N., Katz, J. N. (1995). What to do (and not to do) with time-series cross-section data. American Political Science Review 89(3), 634-647. 
Beramendi, P. (2007). Inequality and the Territorial Fragmentation of Solidarity. International Organization 61(4), 783-820.

Bodman, P., Hodge, A. (2010). What Drives Fiscal Decentralization? Further Assessing the Role of Income. Fiscal Studies 31(3), 373-404.

Bolton, P. Roland, G. (1997). The breakup of nations: a political economy analysis. Quarterly Journal of Economics 112(4), 1057-1090.

Brender, A., Drazen, A. (2009). Do leaders affect government spending priorities? NBER Working Paper n. 15368.

Cameron, D.R. (1978). The Expansion of the Public Economy: A Comparative Analysis. American Political Science Review 72, 1243-1261.

Campos, J., Ericsson, N.R., Hendry, D.F. (2005). General-to-specific modelling: an overview and selected bibliography. Board of Governors of the Federal Reserve System, International Finance Discussion Papers 838.

Cassette, A., Paty, S. (2010). Fiscal decentralization and the size of government: a European country empirical analysis. Public Choice, 143(1-2), 173-189.

Creedy, J., Moslehi, S. (2009). Modelling the composition of government expenditure in democracies. European Journal of Political Economy 25(1), 42-55.

Dafflon, B. (1992). The assignment of functions to decentralized government: from theory to practice. Environment and Planning C: Government and Policy 10(3), 283-298.

De Mello, L. (2005). Globalization and fiscal federalism: does openness constrain subnational budget imbalances? Public Budgeting and Finance 25(1), 1-14.

Diaz-Cayeros, A., Mcelwain, K.M., Romero, V., Siewierski, K.A. (2002). Fiscal Decentralization and Particularistic Spending Across Countries. Paper presented at the Conference on "Comparative Analysis of Political Institutions", Princeton University, Princeton, NJ, USA, 18-19 April 2002.

Eyraud, L., Lusinyan, L. (2013). Vertical fiscal imbalances and fiscal performance in advanced economies. Journal of Monetary Economics 60(5), 571-587.

Faguet, J.P. (2004). Does decentralization increase government responsiveness to local needs? Evidence from Bolivia. Journal of Public Economics 88, 867-893. 
Fiva, J.H. (2006). New evidence on the effect of fiscal decentralization on the size and composition of government spending. FinanzArchiv 62(2), 250-280.

Garrett, G., Rodden, J. (2003). Globalization and fiscal decentralization, in Kahler, M. and Lake, D.A. (eds) Governance in a Global Economy: Political Authority in Transition, Princeton, Princeton University Press, 87-109.

Gemmell, N., Kneller, R., Sanz, I., (2013). Fiscal decentralization and economic growth: spending versus revenue decentralization. Economic Inquiry 51, 1915-1931.

Gordon, R. (1983). An optimal taxation approach to fiscal federalism. Quarterly Journal of Economics 95(4), 567-86.

IMF (2011). Measuring fiscal decentralization - exploring the IMF's databases. Working Paper n. 126.

Jiménez-Rubio, D. (2010). Is fiscal decentralization good for your health? Evidence from a panel of OECD countries. HEDG Working Paper 10/30.

Jin, J., Zou, H., (2002). How does fiscal decentralization affect aggregate, national, and subnational government size? Journal of Urban Economics 52, 270-293.

Kappeler, A., Välilä, T. (2008). Fiscal Federalism and the Composition of Public Investment in Europe. European Journal of Political Economy 24, 562-570.

Keen, M., Marchand, M. (1997). Fiscal Competition and the Pattern of Public Spending. Journal of Public Economics 66, 33-53.

Letelier, L. (2005). Explaining fiscal decentralization. Public Finance Review 33, 155-183.

Milesi-Ferretti G.M., Perotti, R., Rostagno, M. (2002). Electoral Systems and the Composition of Public Spending. Quarterly Journal of Economics 117, 609-657.

Musgrave, R. (1959). The Theory of Public Finance: A Study in Public Economy. New York, McGraw-Hill.

Neyapti, B. (2010). Fiscal decentralization and deficits: International evidence. European Journal of Political Economy, 26(2), 155-166.

Oates, W.E. (1972). Fiscal Federalism. Harcourt Brace, New York, NY. 
OECD (2006). Intergovernmental Transfers and Decentralized Public Spending. Working Paper 3, Network on Fiscal Relations Across Levels of Government, OECD, Paris.

OECD (2009). Tax and Grants: on the Revenue Mix of Sub-central Governments. Working Paper 7, Network on Fiscal Relations Across Levels of Government, OECD, Paris.

OECD (2012). Decentralization and Economic Growth. Working Paper 4, Network on Fiscal Relations Across Levels of Government, OECD, Paris.

Panizza, U. (1999). On the Determinants of Fiscal Centralization: Theory and Evidence. Journal of Public Economics 74(1), 97-139.

Persson, T., Tabellini, G. (1999). The Size and Scope of Government: Comparative Politics with Rational Politicians. European Economic Review 43, 699-735.

Persson, T., Tabellini, G. (2003). The Economic Effects of Constitutions. MIT Press, Cambridge.

Proud-homme, R. (1995). The dangers of decentralization. The World Bank Research Observer 10(2), 201-220.

Prohl, S., Schneider, F. (2009). Does decentralization reduce government size? A quantitative study of the decentralization hypothesis. Public Finance Review, 37(6), 639-664.

Rodden, J. (2003). Reviving Leviathan: fiscal federalism and the growth of government. Industrial Organization 57(4), 695-729.

Rodden. J. (2010). Federalism and interregional redistribution, in Bosch, N., Espasa, M., and Solé Ollé, A. (eds) The Political Economy of Inter-Regional Fiscal Flows, Cheltenham, Glos, Edward Elgar, 191-219.

Rodrik, D. (1998). Why do more open economies have bigger governments? Journal of Political Economy 106(5), 997-1032.

Rodríguez-Pose, A., Tijmstra, S.A.R., Bwire, A. (2009). Fiscal Decentralization, Efficiency, and Growth. Environment and Planning A 41, 2041-2062.

Sacchi, A., Salotti, S. (2013). How Regional Inequality Affects Fiscal Decentralization: Accounting for Sub-Central Governments Autonomy. Environment \& Planning C: Policy \& Government, DOI 10.1068/c1241r, forthcoming. 
Sanz, I., Velázquez, F. (2002). Determinant of the Composition of Government Expenditure by Functions. European Economy Group WP 13. Universidad Complutense de Madrid, Madrid Shelton, C.A. (2007). The Size and Composition of Government Expenditure. Journal of Public Economics 91(11-12), 2230-2260.

Stegarescu, D. (2005). Public Sector Decentralization: Measurement Concepts and Recent International Trends. Fiscal Studies 26(3), 301-333.

Stegarescu, D. (2009). The Effects of Economic and Political Integration on Fiscal Decentralization: Evidence from OECD Countries. Canadian Journal of Economics 42(2), 694-718.

Stigler, G. (1957). Tenable Range of Functions of Local Public Sector. Federal Expenditure Policy for Economic Growth and Stability. Joint Economic Committee, Washington, DC. Reprinted in Phelps, E.S (ed.), Private Wants and Public Needs, rev. ed., 1965.

Swank, D. (1998). Funding the Welfare State: Globalization and the Taxation of Business in Advanced Market Economies. Political Studies 46(4), 671-692.

Tanzi, V. (2000). On Fiscal Federalism: Issues to Worry About. Mimeo

Ter-Minassian, T. (1997). Fiscal Federalism in Theory and Practice. International Monetary Fund, Washington D.C.

Tiebout, C. (1956). A pure theory of local expenditures. Journal of Political Economy, 64(5), 416424.

Treisman, D. (2006). Explaining Fiscal Decentralisation: Geography, Colonial History, Economic Development and Political Institutions. Commonwealth \& Comparative Politics 44(3), 289-325.

Wallis, J., Oates, W.E. (1988). Decentralization in the Public Sector: An Empirical Study of State and Local Government, in Rosen, H. (ed.) Fiscal Federalism: Quantitative Studies, Chicago, University of Chicago Press, 5-28.

Weingast, B.R. (2009). Second Generation Fiscal Federalism: the Implications of Fiscal Incentives. Journal of Urban Economics 65(3), 279-293.

Wibbels, E. (2005). Decentralized governance, constitution formation, and redistribution. Constitutional Political Economy 16(2), 161-188. 
Tables

Table 1 - Expenditure decentralization by function, FE estimation, annual data

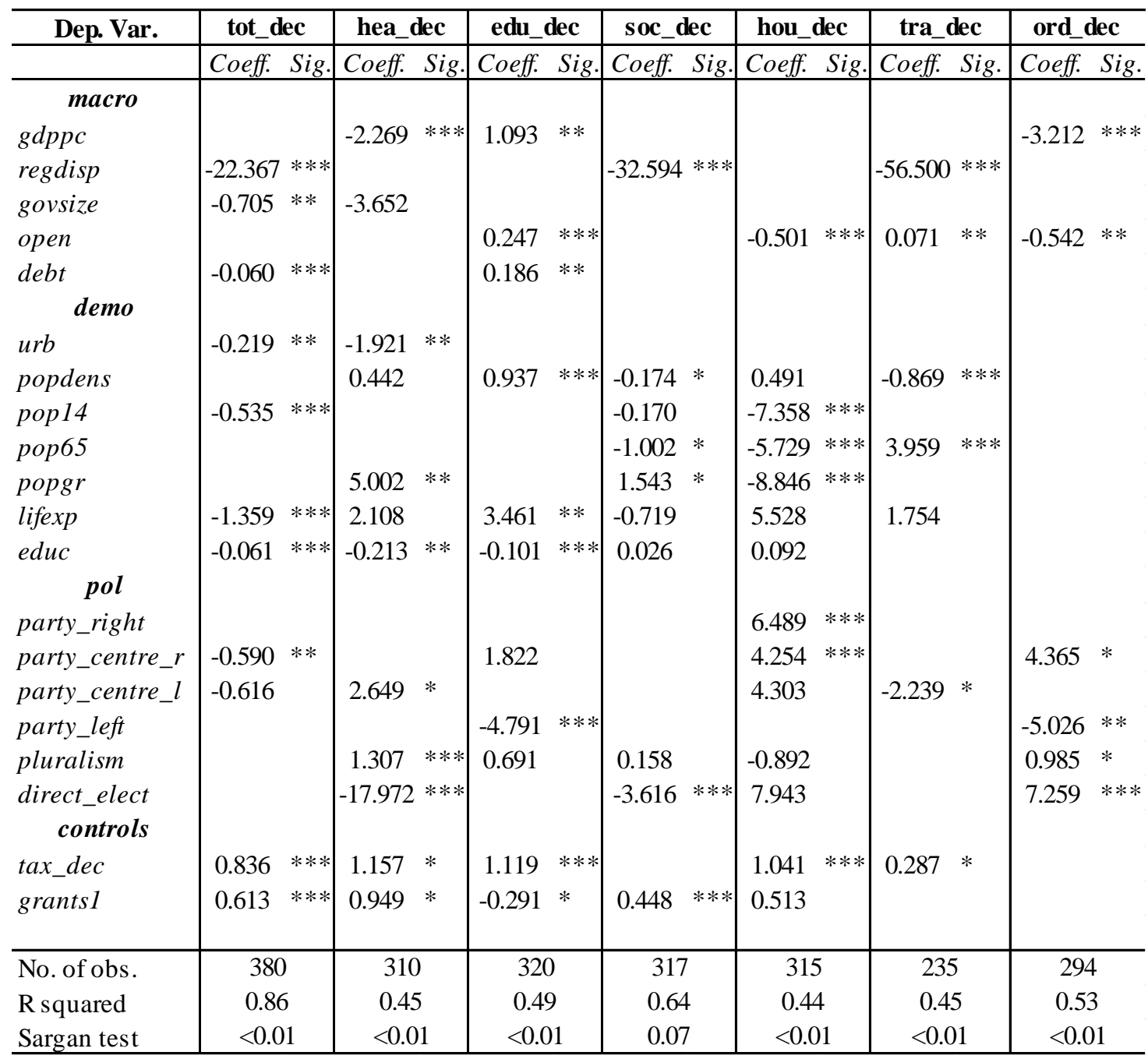

Note - $(* * *),(* *),(*)$ denote significance at $1 \%, 5 \%$ and $10 \%$, respectively. Country dummies, time fixed effects and a constant are included but not reported. Within R-squared is reported. The $p$-values of the Sargan test are reported. 
Table 2 - Expenditure decentralization by function, two-step efficient GMM estimation, annual data

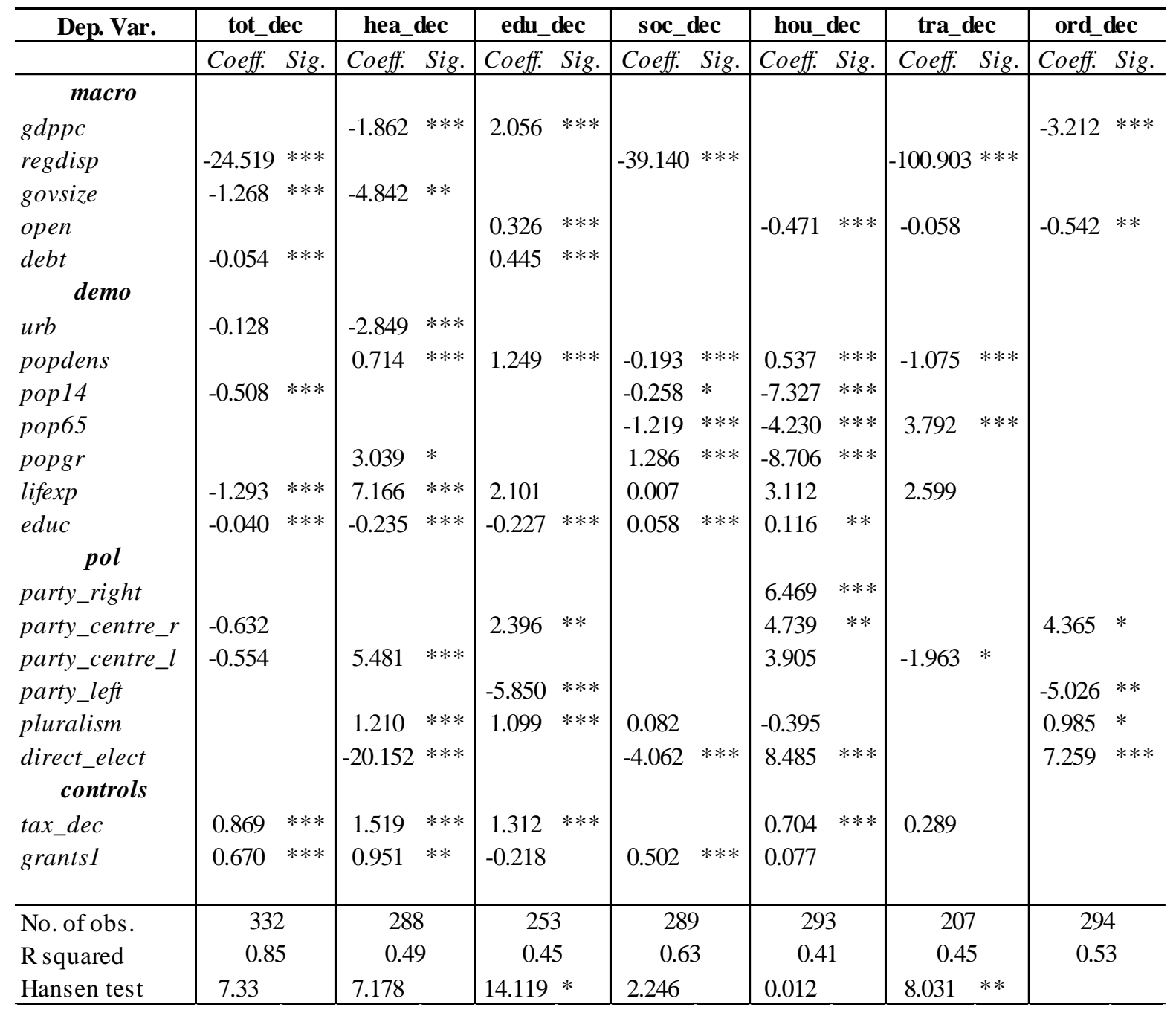

Note - $(* * *),(* *),(*)$ denote significance at $1 \%, 5 \%$ and $10 \%$, respectively (based on small sample statistics). Country dummies, time fixed effects and a constant are included but not reported. Within R-squared is reported. Note that the ord_dec specification results are equal to those in Table 1, as there are no endogenous variables included in the model. We treat educ as endogenous in the $e d u \_d e c$ specification only (where we add the fourth lags of the endogenous variables to the set of instruments to improve diagnostics). 
Table 3 - Expenditure decentralization by function, FE estimation, three-year periods

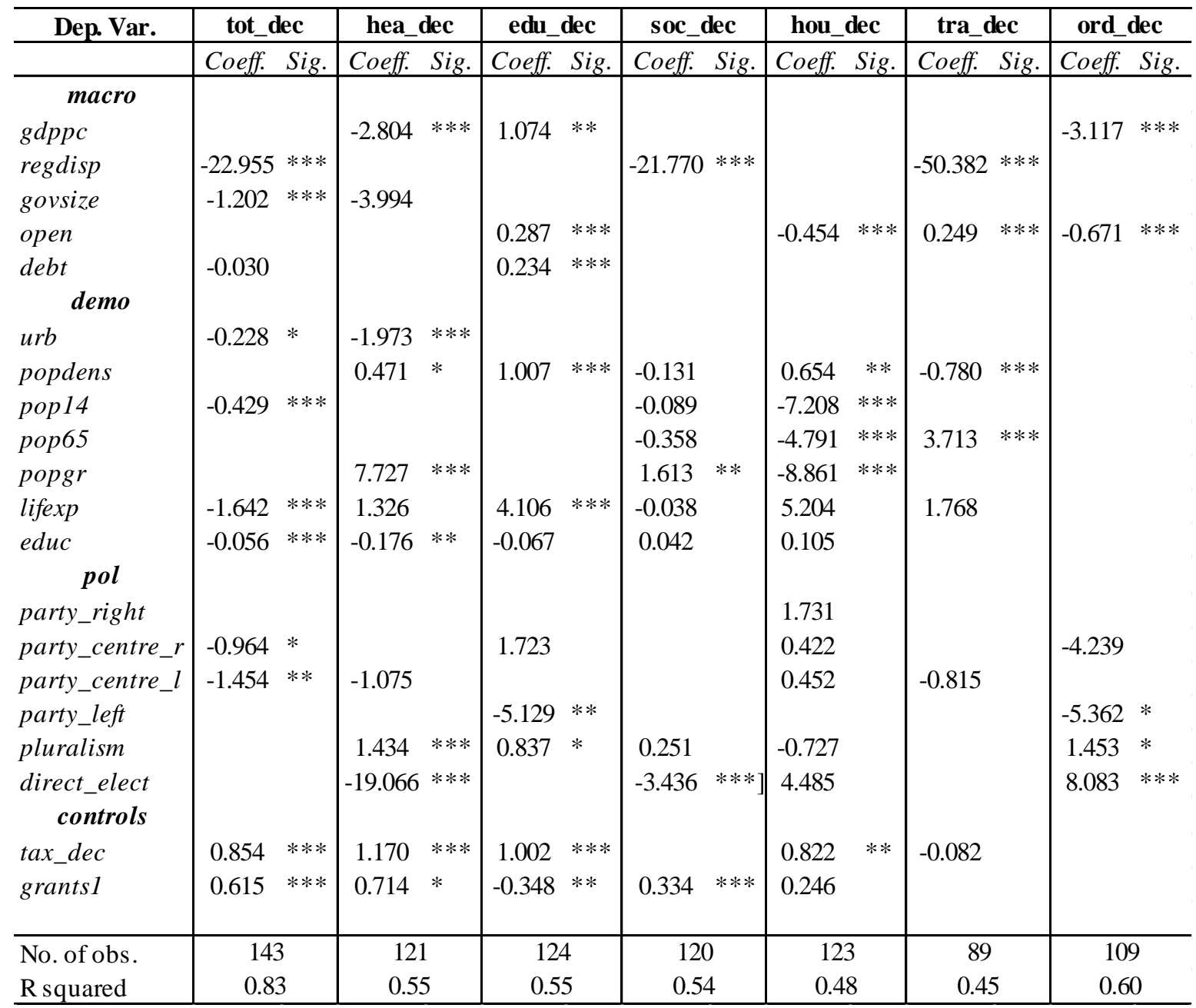

Note $-(* * *),(* *),(*)$ denote significance at $1 \%, 5 \%$ and $10 \%$, respectively. Country dummies, time fixed effects and a constant are included but not reported. Within R-squared is reported. 
Table 4 - Sub-national expenditure composition, FE estimation, annual data

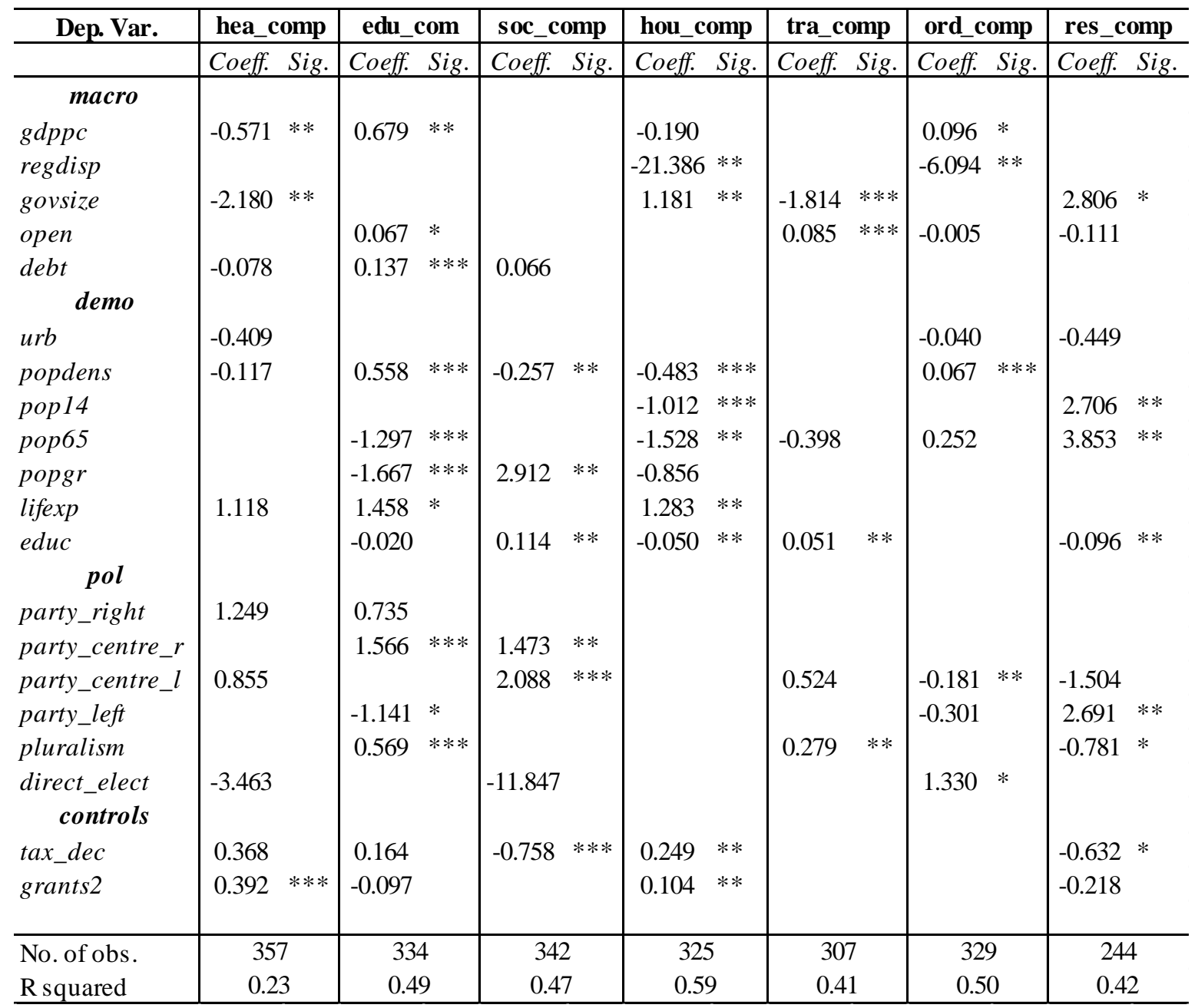

Note $-(* * *),(* *),(*)$ denote significance at $1 \%, 5 \%$ and $10 \%$, respectively. Country dummies, time fixed effects and a constant are included but not reported. Within R-squared is reported. 